\title{
Why Do Past Disabilities Still Haunt the Newly Healthy?
}

\author{
UMUT OGUZOGLU \\ Department of Economics, University of Manitoba \& IZA*
}

\begin{abstract}
A dynamic labour force participation model is used to estimate the impact of disability shocks on labour force participation using a longitudinal sample drawn from the National Population Health Survey. Findings suggest that state dependence play a crucial role in how temporary disabilities can have long lasting employment effects. A disability shock that last only one period is shown to lower labour force participation up to 3 additional periods. Findings are in support of policies that promote greater labour force attachment for individuals with disabilities.
\end{abstract}

Keywords: dynamic panel data, disability, labour force participation, NPHS

JEL Classifications: J22; I10; C33

\section{Introduction}

Strong associations between having a disability and poor employment outcomes are well documented (Jones, 2006). For example, in Canada, only $49 \%$ of 24 to 65 year olds with disability are employed, compared with $79 \%$ of working age persons without a disability (Statistics Canada, 2014). What should also be alarming for policy makers is the fact that individuals continue to have poor employment outcomes long after they recover from disabling health conditions. Longitudinal evidence suggests that, for most, work limiting disability is not permanent and therefore return-to-work should be attainable (Kapteyn et al 2008; Gannon 2005; Oguzoglu, 2010). However, this -it seems- is not often the case. Adverse employment effect of a temporary disability persists many years after individuals recover from disabling health conditions. In Canada, Galarneau and Ridulescu (2009) show that, compared to individuals who have never reported a disability, persons who are currently not-disabled but had a disability episode in the past are less likely to work, and when they do work, they report

\footnotetext{
*Associate Professor, Department of Economics, University of Manitoba; umut.oguzoglu@umanitoba.ca Statistics Canada Disclaimer: This data product is provided as-is, and Statistics Canada makes no warranty, either express or implied, including but not limited to, warranties of merchantability and fitness for a particular purpose. In no event will Statistics Canada be liable for any direct, special, indirect, consequential or other damages, however caused.

(C) 2020 Umut Oguzoglu. Licensed under the Creative Commons Attribution - Noncommercial 3.0 Licence (http://creativecommons.org/licenses/by-nc/3.0/. Available at http: //rofea.org.
} 
lower hours of work and earnings. Charles (2003) and Mok et al (2008) report similar persistent disability effects using data from the US.

One potential factor contributing to the long-lasting effect of a temporary disability may be the highly persistent nature of employment behaviour. Since working today is one of the strongest predictors of work in the future (Heckman and Borjas, 1980; Hyslop, 1999), a disability shock that lowers the likelihood of work now can have an adverse effect on the likelihood of future work even in the absence of a future disability. This may be because lack of labour market exposure while disabled may cause job-specific human capital loss assuming that individual cannot change employer or occupation in the short-run in order to accommodate work limitations imposed by the health conditions, or it can send a bad signal to potential employers about the employability or commitment of the individual (Oguzoglu, 2010).

The main objective of this paper is to illustrate the long-lasting impact of a temporary disability, using a dynamic labour participation model. A longitudinal sample drawn from Canadian National Population Health Survey (NPHS) is used to estimate a dynamic panel probit model. Canadian research that examine the impact of disability on employment outcomes of Canadians has been relatively scarce and often relied on cross-sectional evidence. Using the Labour Market Activity Survey, Hum and Simpson (1996) report a negative association between disability and various employment outcomes. Campolieti (2002) shows that disability play a major role in labour force participation decisions of older men in the first NPHS. Since, cross-sectional surveys are a snapshot in time, these studies may not fully capture the dynamic relationship between disability and labour force status: both potentially time varying characteristics. Although their focus is not on disability, one notable exception is Au et al (2005), who use a static panel data model to investigate the role of health in retirement decisions. To my knowledge, the current article is the first paper that utilises dynamic panel data methodology to estimate the employment impact of disability for Canada.

The results are consistent with the earlier findings from the UK (Jones et al, 2018a; Jones et al 2018b), Ireland (Gannon, 2005), the US (Kapteyn et al., 2008), and Australia (Oguzoglu, 2010; Oguzoglu, 2016) in the sense that: (1) labour force status is highly state dependent, and (2) disability has a significant negative effect on employment behaviour even after lagged employment status, demographic characteristics and unobserved heterogeneity are controlled for.

The results imply that by lowering the current likelihood of labour force participation, an even a short-lived disability episode can have a long-lasting impact. This may partly explain poor employment outcomes for those with past disability episodes but otherwise currently healthy. Naturally, the absence of participation in the past can be due to shocks other than disability. In order to control for other factors associated with joblessness, I simulate the impact of a one period only disability shock using the dynamic panel data estimates and contrast the 


\section{OGUSOGLU Why Do Past Disabilities Still Haunt the Newly Healthy?}

findings against results simulated by a static model. I show that a one period only disability shock can lower labour force participation up to 3 periods for men and women who no longer report a disability. The findings are in support of policies that encourage greater labour market attachment for Canadians with work limiting disabilities.

The paper is organized as follows: Section 2 introduces the econometric model, Section 3 describes the sample and the disability measure used, Section 4 presents the models estimates and the simulation results. Section 5 concludes.

\section{Methodology}

In order to capture the role of state dependence in prolonging the impact of a disability shock the following dynamic labour force participation model is estimated ${ }^{1}$ :

$$
\begin{gathered}
y_{i t}^{*}=\gamma y_{i t-1}+\beta X_{i t}+\delta D_{i t}++\alpha_{i}+\epsilon_{i t} \\
\epsilon_{i t} \sim N\left(0, \sigma_{i t}\right) ; \alpha_{i} \sim N\left(0, \sigma_{\alpha}\right)
\end{gathered}
$$

where $y_{i t}^{*}$ is the latent labour force status of individual $i$ at time $t, y_{i t-1}$ is the lagged labour force participation that is equal to one if individual $i$ participates in the labour force (e.g. employed or unemployed) at $t-1$ and zero otherwise. $D_{i t}$ is the binary disability status that is equal to 1 if individual $i$ reports a disability at time $t$. $X_{i t}$ are demographic characteristics such as age, age squared, indicators for household size, indicator for capital income, marital status, dependent children, indicators for level of education (no high school, high school, post secondary, university degree), immigration status, and province of residence. $\alpha_{i}$, the individual specific random effect that follows a normal distribution with mean 0 and variance $\sigma_{\alpha}$, and $\epsilon_{i t}$ is the normally distributed error term that varies across individuals and time.

The models are estimated using the dynamic panel probit estimator suggested by Woolridge (2005). The approach requires inclusion of labour force status from the first cycle and time averages of $X_{i t}$ to be included as additional regressors. Models were estimated for men and women separately. For comparison, the static counterparts of (1), where $y_{i, t-1}$ is omitted from the models, are also estimated ${ }^{2}$.

\footnotetext{
${ }^{1}$ This paper abstracts away from two important issues related to employment outcomes of individuals with disability: (1) the labour demand side factors such as discrimination by employers, or workplace accommodation of individuals with disability, and (2) work disincentives created by the social security system. See Jones (2008) for available evidence.

${ }^{2}$ Models include longitudinal weights provided by NPHS to deal with possibility of attrition bias.
} 


\section{Data and the Sample}

The data that is used in this paper is drawn from the first 8 bi-annual cycles of the NPHS (1994 to 2008). The NPHS is a nationally representative longitudinal survey that is collected biannually by Statistics Canada. In the first cycle, NPHS longitudinal sample included 17,276 persons from all ages, by cycle $8,70.7 \%$ of the original sample from the first cycle remained ${ }^{3}$.

The main focus of the NPHS is health outcomes and utilisation of health services; therefore, it contains very detailed information on health and health service utilization. Another novel feature of the NPHS is that it includes an objective Health Utility Index Mark 3 (HUI3). HUI3 uses 32 detailed health characteristics in order to construct a continuous health index and it is widely used by health professionals (Horsman et al 2003) ${ }^{4}$.

NPHS also provide demographic and employment related characteristics, although these are much less detailed than what is available in surveys that tract socioeconomic and employment outcomes, such as the Survey of Labour and Income Dynamics (SLID) ${ }^{5}$. Additionally, the sample size in the NHPS is much smaller than that of the SLID (Buckley et al., 2006).

The sample used in this paper contains an unbalanced sample of 2,847 men and 3,551 women aged 24 to $64^{6}$. The final sample is achieved by removing all individuals with missing information and those with less than three consecutive bi-annual observations. Even though, the sample selection rule is much less restrictive than a balanced sample, it is possible that some individuals with severe disabilities may drop out of the sample which could potentially bias the effect of disability downwards. In order to address this problem all models include longitudinal weights.

I adopt the same disability measured used in Campolieti (2002) which is identified according to the following activity limitation question in the NPHS:

"Because of a long term physical or mental health condition, are you limited in the kind or amount of activity you can do at home/school or work?"

\footnotetext{
${ }^{3}$ Note that this attrition rate refers to the entire NPHS sample covers all ages. Given the focus on the working age population, attrition rate for the sample used in this paper is much lower. Due to confidentiality issues, I am not able to report attrition rate for the actual sample.

${ }^{4}$ See Tambay and Catlin, 1995 and Campolieti 2002 for details on sample design and interview procedures in NPHS.

${ }^{5}$ SLID, for example, is more suited to explore the impact of disability on occupational change.

${ }^{6}$ Focus on this age group is in line with how Statistics Canada report employment statistics by disability. One potential concern may be that older individuals are more likely to report disability and more likely to be aged out of the sample. Note that, all models include age controls.
} 


\section{OGUSOGLU Why Do Past Disabilities Still Haunt the Newly Healthy?}

The above definition of disability is close to the definition used in the American Disability Act in the sense that a person with a disability is a person who has a physical or mental impairment that substantially limits one or more major life activities. According to this measure, 19 percent of men and 20 percent of women in the sample report a disability.

It is important for the main purpose of this paper that individuals can report a disability temporarily, even though the wording of the interview question (e.g. "long term [...] health condition") may imply a permanent limitation. I assume that limitation caused by health conditions can be temporary even if the health conditions themselves are long term. In fact, only around 4 percent of individuals in the sample are permanently disabled; that is, they report disability during the entire time that they are observed, while around 40 percent report disability irregularly, and around 56 percent never report a disability.

Self-assessed health measures drew criticism in the literature due to the possibility of justification bias (over-reporting a disability to rationalise non-work) ${ }^{7}$. However, self-reported health measures have been shown to be a strong predictor of medically determined health status (Nagi, 1969; and LaRue et al., 1979). Oguzoglu (2012) compared two self-reported disability measures: a work limitation measure where disability is asked in the context of employment and the activity limitation similar to the disability indicator used in this paper. This showed that justification bias in activity limitation measures are minimal ${ }^{8}$. In Table 1 , detailed health measures available in the NPHS are listed by disability status. Compared to persons without a disability, disabled persons have higher prevalence of specific health conditions, score lower in the HUI3 health index ${ }^{9}$ and are more likely to be out of the normal BMI range.

Table 2 reports labour force participation rates by disability status in the sample. It is evident that disability is associated with lower labour force participation for both men and women. Compared to 93.6 (79.3) percent of men (women) without a disability only 71 (60.3) percent of men (women) with a disability participate in the labour force. In Table 3, demographic characteristics of the sample is presented by disability status. The disabled sample tend to be older, less educated and less likely to be a recent immigrant than the not disabled sample. Moreover, disabled women are less likely to be married and less likely to have dependent children. There are no noticeable regional differences across disability status.

\footnotetext{
${ }^{7}$ Jones et al. (2008) provide a detailed survey of literature that analyse the self-reported disability.

${ }^{8}$ In order to address endogeneity issues, a linear probability model is also estimated where the disability measure is replaced by a predicted disability from a first-stage model of $D_{i t}$ on specific health conditions. Results, which are available upon request, are consistent with the main conclusion of this paper.

${ }^{9}$ HUI3 is a continuous summary measure of specific health conditions and health utilisation. It takes values between 0 (worst health) and 100 (excellent health). See Horsman et al. (2003) for details.
} 
Review of Economic Analysis 12 (2020) 331-344

Table 1: Detailed Health Measures by Self-Assessed Disability

\begin{tabular}{|l||c|c|c|c|}
\hline \multicolumn{1}{|c||}{} & \multicolumn{2}{c|}{ MEN } & \multicolumn{2}{c|}{ WOMEN } \\
\cline { 2 - 5 } & Disabled & Not disabled & Disabled & Not disabled \\
\hline \hline \multirow{2}{*}{ HUI3 Index } & 75 & 94 & 72 & 93 \\
\hline Has BMI<20 or >34 (\%) & 12 & 7 & 25 & 20 \\
\hline Have Health Condition (\%) & & & & 17 \\
\hline Respiratory illness & 11 & 6 & 43 & 7 \\
\hline Arthritis & 31 & 7 & 39 & 11 \\
\hline Back pain & 37 & 11 & 18 & 9 \\
\hline High Blood Pressure & 19 & 8 & 23 & 13 \\
\hline Migraines & 9 & 4 & 6 & 2 \\
\hline Diabetes & 9 & 3 & 7 & 1 \\
\hline Heart condition & 10 & 2 & 3 & 1 \\
\hline Cancer & 3 & 0 & 5 & 1 \\
\hline Vision problems & 4 & 1 & & \\
\hline
\end{tabular}

Note: Statistics are calculated using a pooled sample of all 8 cycles of NPHS. Population weights provided by the NPHS are used. HUI3 is a continuous summary measure of specific health conditions and health utilisation. It takes values between 0 (worst health) and 100 (excellent health).

\section{Estimation Results}

In Table 4, the estimated coefficients of lagged labour force participation and disability from model (1) are reported. For comparison, estimates from a static version of model (1), when $y_{i, t-1}$ is excluded from the estimation, are also reported ${ }^{10}$. Panel B of Table 4 presents average partial effects (APE) of the variables of interest ${ }^{11}$.

The dynamic model suggests that there is very strong state dependence in labour force behaviour. The estimated coefficient of the lagged labour force participation is positive and highly significant. Independent of disability status and other demographic controls, individuals who were labour force participants in the past are more likely to be current labour force

\footnotetext{
${ }^{10}$ Full results are in Appendix. Labour force participation is increasing in age at a decreasing rate. Being married increases the likelihood of participation for men but not for women. Labour force participation is decreasing in number of dependent children. Education increases the likelihood of participation. Immigrant men are more likely to be in the labour force than Canadian born men, while immigrant women are more likely to be out of the work force than Canadian born women.

${ }^{11}$ APE are evaluated at the average characteristics of the sample. Random effects are set to zero, individual is assumed to be not disabled at $\mathrm{t}-1$.
} 
OGUSOGLU Why Do Past Disabilities Still Haunt the Newly Healthy?

Table 2: Labour Force Participation by Disability and Sex (\%)

\begin{tabular}{|c||c|c|}
\hline & MEN & WOMEN \\
\hline \hline Disabled & 71.13 & 60.38 \\
\hline Not Disabled & 93.64 & 79.38 \\
\hline
\end{tabular}

Note: Statistics are calculated using a pooled sample of all 8 cycles of NPHS. Population weights provided by the NPHS are used. Numbers represent percentage of individuals who are labour force participants within a given Disability by Sex category.

Table 3: Mean of Demographic Characteristics by Disability Status and Gender

\begin{tabular}{|c|c|c|c|c|}
\hline & \multicolumn{2}{|c|}{ MEN } & \multicolumn{2}{|c|}{ WOMEN } \\
\hline & Disabled & Not disabled & Disabled & Not disabled \\
\hline Age & 42.4 & 46.4 & 42.2 & 46.2 \\
\hline Household Size=1 & 0.15 & 0.13 & 0.15 & 0.09 \\
\hline Household Size=2 & 0.32 & 0.27 & 0.37 & 0.30 \\
\hline Household Size $=3$ & 0.19 & 0.21 & 0.22 & 0.23 \\
\hline Household Size=4 & 0.21 & 0.24 & 0.16 & 0.24 \\
\hline Household Size $>4$ & 0.13 & 0.15 & 0.10 & 0.14 \\
\hline Have capital income & 0.20 & 0.21 & 0.20 & 0.19 \\
\hline Own house & 0.74 & 0.76 & 0.72 & 0.75 \\
\hline Married & 0.62 & 0.62 & 0.56 & 0.62 \\
\hline Have kids & 0.39 & 0.53 & 0.34 & 0.58 \\
\hline \multicolumn{5}{|c|}{ Education: } \\
\hline No high school & 0.06 & 0.02 & 0.05 & 0.03 \\
\hline High school & 0.13 & 0.13 & 0.14 & 0.16 \\
\hline Post-secondary & 0.28 & 0.26 & 0.30 & 0.26 \\
\hline University Degree & 0.38 & 0.46 & 0.38 & 0.44 \\
\hline White & 0.46 & 0.51 & 0.48 & 0.50 \\
\hline Immigrant & 0.14 & 0.18 & 0.14 & 0.19 \\
\hline \multicolumn{5}{|c|}{ Province: } \\
\hline Quebec & 0.24 & 0.27 & 0.20 & 0.27 \\
\hline Prairie Provinces & 0.18 & 0.16 & 0.18 & 0.16 \\
\hline Ontario & 0.38 & 0.37 & 0.37 & 0.37 \\
\hline British Columbia & 0.11 & 0.12 & 0.15 & 0.12 \\
\hline Eastern Provinces & 0.05 & 0.05 & 0.05 & 0.05 \\
\hline
\end{tabular}

Note: Statistics are calculated using a pooled sample of all 8 cycles of NPHS. Population weights provided by the NPHS are used. All variables except age and age ${ }^{2}$ are binary indicators. Variable White refers to individuals who self-identify as White, this may not reflect to racial distribution in Canada. 
Review of Economic Analysis 12 (2020) 331-344

Table 4: Dynamic Panel Data Results, Variables of Interest

\begin{tabular}{|lcccc|}
\hline \multicolumn{5}{c|}{ Panel A: Estimates } \\
\hline & Men & Women & \\
\hline & Dynamic & Static & Dynamic & Static \\
\hline \hline LF $_{\mathrm{t}-1}$ & $1.880^{* * *}$ & & $1.563^{* * *}$ & \\
\hline & $(0.00198)$ & $(0.00143)$ & \\
\hline Disabled $_{\mathrm{t}}$ & $-0.654^{* * *}$ & $-1.08^{* * *}$ & $-0.404^{* * *}$ & $-0.620^{* * *}$ \\
\hline & $(0.00141)$ & $(-0.00225)$ & $(0.00114)$ & $(0.00162)$ \\
\hline & & Panel B: Average Partial Effects & \\
\hline LF $_{\mathrm{t}-1}$ & 0.619 & & 0.672 & -0.221 \\
\hline Disabled $_{\mathrm{t}}$ & -0.113 & -0.102 & -0.147 & \\
\hline
\end{tabular}

Note: ${ }^{* * *}$ implies significance at $1 \%$. Average Partial Effects are computed at the average characteristics of the sample. Models include demographic controls listed in Table 3, year dummies and individual time averages of control variables.

participants. APE suggests that men (women) who work in the last period are around 62 (67) percentage points more likely to be current labour force participants compared to men (women) who did not participate in the labour force in the previous period.

From the estimation results, it is evident that disability has a significant adverse impact on labour force participation even after lagged labour force status is controlled for. The estimated coefficient of the disability status, $D_{i t}$, is negative and highly significant in both dynamic and static models. According to APE of the static model, there is a considerable difference in magnitude of how men and women are affected by a disability shock: having a disability decreases the likelihood of labour force participation by 10 percentage points for men and by 22 percentage points for women. The differential impact of disability between men and women largely disappears when lagged labour force participation is controlled for. The disability effect estimated by the dynamic models are slightly larger than those from the static model for men, around 11.3 percentage points, and much smaller for women, an approximate 16 percentage point decrease in the likelihood of labour force participation.

\subsection{Model Simulations}

The large and negative impact of disability presented in the previous section measures only the immediate effect of a disability. The intertemporal effect of a disability shock on labour force participation can be much more substantial due to high state dependence of employment behaviour. In this section, I demonstrate how strong state dependence of employment behaviour implied by the dynamic model results can prolong impact of a temporary disability shock. This 


\section{OGUSOGLU Why Do Past Disabilities Still Haunt the Newly Healthy?}

can partly explain poor employment outcomes of currently not-disabled individuals with past episodes of disability.

Put simply, a disability shock has an immediate impact on labour force participation at time $t$, and since labour force participation is highly persistent, a low participation at $t$ is likely to cause lower participation at $t+1$. Naturally, lower participation in the previous period may be due to shocks other than disability. In order to control for the confounding factors that may cause joblessness, I simulate the effect of a temporary disability using model estimates as follows: I assume that an individual with sample-average characteristics participates in the labour force and is not disabled at time $t=1$. This individual receives a disability shock at $t=$ 2 , and at $t=3$ is no longer disabled. Simulations are carried out for men and women using corresponding dynamic and static model estimates separately ${ }^{12}$.

Figure 1 and Figure 2 present the simulated change in likelihood of labour force participation due to a disability for men and women, respectively. As expected, the lack of lagged labour force participation translates into a recovery of the likelihood of labour force participation immediately after the disability shock. The dynamic models, however, show that the impact of a temporary disability takes up to $t=5$ to be fully realised. This is purely due to the feedback effect that is captured by the lagged labour force status. Past disability has a lingering effect on labour force participation due to the dynamic nature of labour force behaviour. Lower labour force exposure in the past (due to a past disability) lowers the likelihood of participation in the future.

Note that due to the simulation setup the intertemporal effects in Figure 1 and Figure 2 are likely to be a lower bound. Most individuals who experience a disability shock remain disabled for more than one period. In the NPHS sample 70 percent of men and women who report a disability in one cycle also report a disability in the following cycle. Therefore, a disability shock that lasts more than one period will likely have a much longer impact than what is implied by the simulation results.

\section{Conclusion}

This paper uses a dynamic labour force participation model to estimate the intertemporal effect of disability for a longitudinal sample drawn from the National Population Health Survey. The main advantage of a dynamic model over a static model is that a dynamic labour force model provides a channel through which current disability can affect future employment. In other

\footnotetext{
${ }^{12}$ The likelihood of labour force participation is simulated using estimated parameters presented in Appendix Table A1. Initially, individuals are assumed to be in the labour force and without a disability and have the characteristics of an average male and female in the sample. First 20 periods of the simulation are discarded, and the disability shock is introduced at period $22^{\text {nd }}$. The Figures 1 and 2 report results from period $21^{\text {st }}$ onwards.
} 
Figure 1: Simulated Change in Likelihood of Labour Force Participation- Male Sample, Disability Shock at $\mathrm{t}=2$

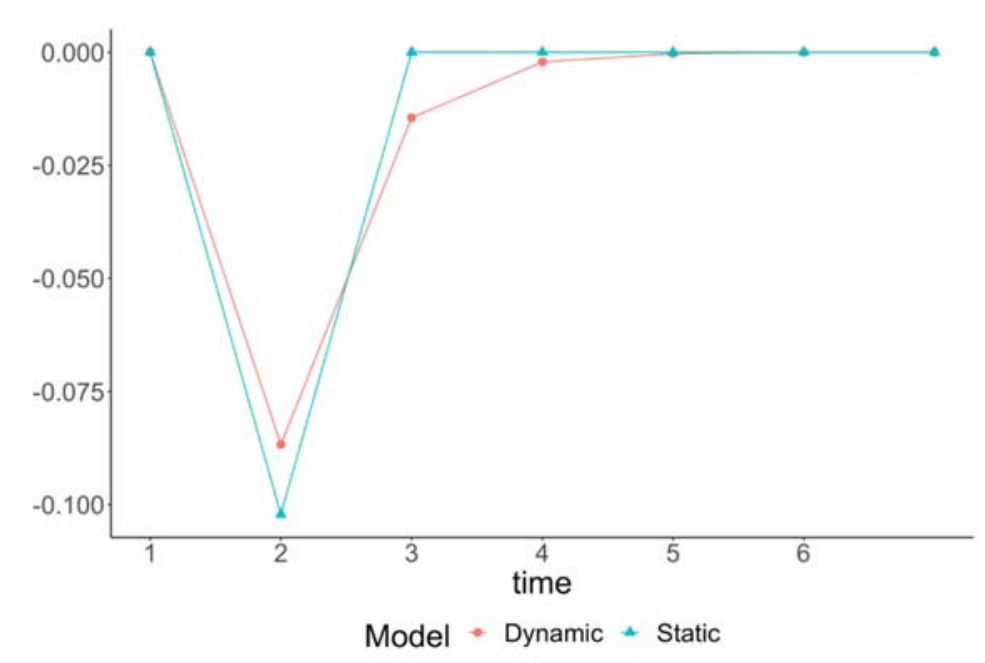

Note: Figures show change in the probability of labour force participation in response to a disability shock at $\mathrm{t}=2$ for a man with average characteristics of the male sample. The individual is assumed to be labour force participant and not-disabled at $\mathrm{t}=1$. The effects simulated by dynamic model are $-0.09,-0.014$ and -0.002 for periods 2,3 and 4 respectively.

Figure 2: Simulated Change in Likelihood of Labour Force Participation- Female Sample, Disability Shock at $\mathrm{t}=2$

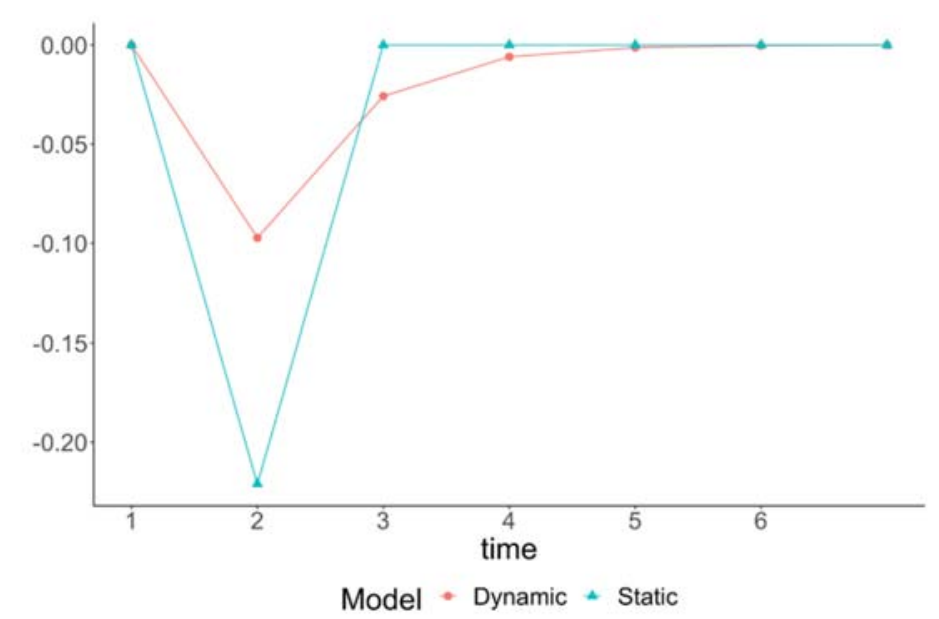

Note: Figures show change in the probability of labour force participation in response to a disability shock at $\mathrm{t}=2$ for a woman with average characteristics of the female sample. The individual is assumed to be labour force participant and not-disabled at $t=1$. The effects simulated by dynamic model are $-0.1,-0.026$ and -0.006 for periods 2,3 and 4 respectively. 


\section{OGUSOGLU Why Do Past Disabilities Still Haunt the Newly Healthy?}

words, being disabled in the current period makes an individual less likely to participate in the labour force and being out of the labour force makes an individual less likely to be a participant in the future. This may partly explain poor employment outcomes of individuals who experienced disability episodes in the past but otherwise currently healthy.

The findings are consistent with earlier findings by Jones et al (2018a), Gannon (2005), Kapteyn et al. (2008), and Oguzoglu (2010, 2016), which show that employment behaviour is highly persistent, and disability negatively affects the likelihood of employment even after past labour force outcomes are controlled for. Moreover, descriptive statistics in this paper also confirm evidence from other countries that the majority of individuals who ever report a disability do so irregularly. This emphasises the need for research to further our understanding of the long run impact of temporary disabilities.

The estimated parameters of the dynamic panel probit model are used to simulate the impact of a temporary disability on the likelihood of labour force participation. The simulated effect based on the dynamic model estimates show that a disability episode that lasts only one period can have an impact on the likelihood of labour force participation up to 3 more periods. This is in contrast with the immediate recovery implied by the simulation based on the static model which does not control for lagged labour force status.

Results from the dynamic model suggest that the prolonged adverse effect of a disability may be partly due to strong state dependence in employment behaviour. This finding has two implications: first, since past labour force participation increases the current likelihood of participation, increasing labour force participation of people at risk of being disabled (or of those who are disabled) is crucial. Secondly, since not being in the labour force is as detrimental to future participation as being disabled, policies that incentivise greater labour force attachment for the disabled individuals may produce positive return-to-work outcomes. Ignoring this will prolong the effect of a temporary disability and slows down economic participation efforts of the disabled community.

\section{References}

Au, D. W. H., Crossley, T. F. and Schellhorn, M., (2005), The Effect of Health Changes and Long-term Health on the Work Activity of Older Canadians, Health Economics, 999-1018.

Buckley, N., Denton, F., Robb, C., and Spencer, B., (2006), Socio-Economic Influences on the Health of Older Canadians, Canadian Public Policy, 59-81.

Charles, K. K., (2003), The Longitudinal Structure of Earnings Losses Among Work-Limited Disabled Workers, Journal of Human Resources, 619-646.

Campolieti, M., (2002), Disability and the Labor Force Participation of Older Men in Canada, Labour Economics, 405-432.

Galarneau, D., and Radulescu, M., (2009), Employment Among the Disabled, Perspectives on Labour and Income. Statistics Canada. 
Gannon B., (2005), A Dynamic Analysis of Disability and Labour Force Participation in Ireland 1995-2000, Health Economics, 925-938.

Horsman, J., Furlong, W., Feeny, D., and Torrance, G., (2003), The Health Utilities Index (HUI): Concepts, Measurement Properties and Applications, Health and Quality of Life Outcomes, 54.

Jones, M.K., Latreille, P.L. and Sloane, P.J., (2006), Disability, Gender and the British Labour Market, Oxford Economic Papers, 407-459.

Heckman, J. J. and Borjas, G. J., (1980), Does Unemployment Cause Future Unemployment? Definitions, Questions and Answers from a Continuous Time Model of Heterogeneity and State Dependence, Economica, 247-283.

Hyslop, D., (1999), State Dependence, Serial Correlation and Heterogeneity in IntertemporalLabor Force Participation of Married Women, Econometrica, 1255-1294.

Hum, D., Simpson, W., (1996), Canadians with Disabilities and the Labour Market. Canadian Public Policy, 285-297.

Jones, M.K., (2008), Disability and The Labour Market: A Review of The Empirical Evidence, Journal of Economic Studies, 405-424.

Jones, M.K., Davies, R. and Drinkwater, S., (2018), The Dynamics of Disability and Work in Britain, The Manchester School, 279-307.

Jones, M.K., Mavromaras, K., Sloane, P. and Wei, Z., (2018), The Dynamic Effect of Disability on Work and Subjective Well-Being, Oxford Economic Papers, 635-657.

Kapteyn, A., Smith, J. P. and van Soest, A., (2008), Dynamics of Work Disability and Pain, Journal of Health Economics, 496-509.

LaRue, A., Bank, L., Jarvik, U. and Hetland, M., (1979), Health in Old Age: How Do Physicians Ratings and Self-Ratings Compare?, Journal of Gerontology, 687-691.

Mok, W.K., Meyer, B.D., Charles, K.K. and Achen, A.C., (2008), A Note on The Longitudinal Structure of Earnings Losses Among Work-Limited Disabled Workers, Journal of Human Resources, 721-728.

Nagi, S., (1969), Congruency in Medical and Self-Assessment of Disability, Industrial Medicine, 27-36.

OECD, (2010), Moving Beyond the Job Crisis, OECD Employment Outlook.

Oguzoglu, U., (2010), Dynamics of Work Limitation and Work in Australia, Health Economics, 656-669.

Oguzoglu, U., (2012), Is there a Better Measure of Self-assessed Disability? , Applied Economics Letters, 1335-1338.

Oguzoglu, U., (2016), Disability and Multi-State Labour Force Choices with State Dependence, Economic Record, 28-46.

Tambay, J.-L. and Catlin G., (1995), Sample Design of the National Population Health Survey - Its Longitudinal Nature, Health Reports, 29-38. 
OGUSOGLU Why Do Past Disabilities Still Haunt the Newly Healthy?

Turcotte, M., (2014), Persons with Disabilities and Employment, Statistics Canada.

Wooldridge, J. M., (2005), Simple Solutions to the Initial Conditions Problem in Dynamic, Non-Linear Panel Data Models with Unobserved Heterogeneity, Journal of Applied Econometrics, 39-54

APPENDIX:

Table A1: Labour Force Model Estimates, Full Results

\begin{tabular}{|c|c|c|c|c|}
\hline & \multicolumn{2}{|c|}{ MEN } & \multicolumn{2}{|c|}{ WOMEN } \\
\hline & Static & Dynamic & Static & Dynamic \\
\hline \multirow[t]{2}{*}{$\mathrm{LF}_{\mathrm{t}-1}$} & & $1.880^{* * *}$ & & $1.563^{* * *}$ \\
\hline & & $(0.0020)$ & & $(0.0014)$ \\
\hline \multirow[t]{2}{*}{ Initial LF } & & $0.413^{* * *}$ & & $0.468^{* * *}$ \\
\hline & & $(0.0029)$ & & $(0.0015)$ \\
\hline \multirow[t]{2}{*}{ Disabled $_{t}$} & $-1.080^{* * *}$ & $-0.654^{* * *}$ & $-0.620^{* * *}$ & $-0.404^{* * *}$ \\
\hline & $(0.0023)$ & $(0.0014)$ & $(0.0016)$ & $(0.0011)$ \\
\hline \multirow[t]{2}{*}{ Age } & $3.072^{* * *}$ & $1.610^{* * *}$ & $1.840^{* * *}$ & $0.906^{* * *}$ \\
\hline & $(0.0166)$ & $(0.0134)$ & $(0.0112)$ & $(0.0094)$ \\
\hline \multirow[t]{2}{*}{$\mathrm{Age}^{2}$} & $-0.561^{* * *}$ & $-0.247^{* * *}$ & $-0.433^{* * *}$ & $-0.200^{* * *}$ \\
\hline & $(0.0015)$ & $(0.0013)$ & $(0.0010)$ & $(0.0009)$ \\
\hline \multirow[t]{2}{*}{ House Size $=1$} & $0.0435^{* * *}$ & $0.128^{* * *}$ & $0.0403^{* * *}$ & $0.101^{* * *}$ \\
\hline & $(0.0057)$ & $(0.0034)$ & $(0.0041)$ & $(0.0029)$ \\
\hline \multirow[t]{2}{*}{ House Size $=2$} & $-0.107^{* * *}$ & $0.0765^{* * *}$ & $0.122^{* * *}$ & $0.124^{* * *}$ \\
\hline & $(0.0049)$ & $(0.0029)$ & $(0.0032)$ & $(0.0022)$ \\
\hline \multirow[t]{2}{*}{ House Size $=3$} & $0.0643^{* * *}$ & $0.0686^{* * *}$ & $0.145^{* * *}$ & $0.0798^{* * *}$ \\
\hline & $(0.0048)$ & $(0.0028)$ & $(0.0029)$ & $(0.0020)$ \\
\hline \multirow[t]{2}{*}{ House Size $=4$} & $-0.0629^{* * *}$ & $0.117^{* * *}$ & $0.0453^{* * *}$ & $0.0419^{* * *}$ \\
\hline & $(0.0044)$ & $(0.0026)$ & $(0.0027)$ & $(0.0018)$ \\
\hline \multirow[t]{2}{*}{ Have Capital Income } & $-0.0855^{* * *}$ & $-0.0458^{* * *}$ & 0.0032 & $-0.0150^{* * *}$ \\
\hline & $(0.0022)$ & $(0.0017)$ & $(0.0016)$ & $(0.0014)$ \\
\hline \multirow[t]{2}{*}{ Own House } & $0.0434^{* * *}$ & $0.0789^{* * *}$ & $-0.170^{* * *}$ & $-0.181^{* * *}$ \\
\hline & $(0.0041)$ & $(0.0030)$ & $(0.0028)$ & $(0.0025)$ \\
\hline \multirow[t]{2}{*}{ Married } & $0.337^{* * *}$ & $0.157^{* * *}$ & $-0.413^{* * *}$ & $-0.274^{* * *}$ \\
\hline & $(0.0052)$ & $(0.0037)$ & $(0.0029)$ & $(0.0024)$ \\
\hline
\end{tabular}


Review of Economic Analysis 12 (2020) 331-344

Table A1 Continued

\begin{tabular}{|c|c|c|c|c|}
\hline & \multicolumn{2}{|c|}{ MEN } & \multicolumn{2}{|l|}{ WOMEN } \\
\hline & Static & Dynamic & Static & Dynamic \\
\hline \multirow[t]{2}{*}{ Have Kids } & $-0.104^{* * *}$ & $-0.0535^{* * *}$ & $-0.302^{* * *}$ & $-0.157^{* * *}$ \\
\hline & $(0.0022)$ & $(0.0015)$ & $(0.0011)$ & $(0.0009)$ \\
\hline \multirow[t]{2}{*}{ High School } & $0.671^{* * *}$ & $0.320^{* * *}$ & $0.475^{* * *}$ & $0.172^{* * *}$ \\
\hline & $(0.0051)$ & $(0.0023)$ & $(0.0038)$ & $(0.0019)$ \\
\hline \multirow[t]{2}{*}{ Post Secondary } & $0.562^{* * *}$ & $0.275^{* * *}$ & $0.531^{* * *}$ & $0.149^{* * *}$ \\
\hline & $(0.0041)$ & $(0.0019)$ & $(0.0033)$ & $(0.0018)$ \\
\hline \multirow[t]{2}{*}{ University Degree } & $0.816^{* * *}$ & $0.373^{* * *}$ & $1.030^{* * *}$ & $0.339^{* * *}$ \\
\hline & $(0.0040)$ & $(0.0018)$ & $(0.0033)$ & $(0.0017)$ \\
\hline \multirow[t]{2}{*}{ White } & $(0.0052)$ & $0.195^{* * *}$ & $0.193^{* * *}$ & $0.155^{* * *}$ \\
\hline & $(0.0069)$ & $(0.0046)$ & $(0.0044)$ & $(0.0035)$ \\
\hline \multirow[t]{3}{*}{ Immigrant } & $0.628^{* * *}$ & $0.178^{* * *}$ & $0.0619^{* * *}$ & $0.0687^{* * *}$ \\
\hline & Static & Dynamic & Static & Dynamic \\
\hline & $(0.0043)$ & $(0.0019)$ & $(0.0030)$ & $(0.0015)$ \\
\hline \multirow[t]{2}{*}{ PRARIE } & $0.780^{* * *}$ & $0.343^{* * *}$ & $0.261^{* * *}$ & $0.0831^{* * *}$ \\
\hline & $(0.0045)$ & $(0.0021)$ & $(0.0032)$ & $(0.0016)$ \\
\hline \multirow[t]{2}{*}{$\mathrm{ON}$} & $0.306^{* * *}$ & $0.128^{* * *}$ & $0.350^{* * *}$ & $0.138^{* * *}$ \\
\hline & $(0.0036)$ & $(0.0016)$ & $(0.0027)$ & $(0.0013)$ \\
\hline \multirow[t]{2}{*}{$\mathrm{BC}$} & $-0.0462^{* * *}$ & $-0.0344^{* * *}$ & $0.341^{* * *}$ & $0.188^{* * *}$ \\
\hline & $(0.0047)$ & $(0.0021)$ & $(0.0035)$ & $(0.0018)$ \\
\hline \multirow[t]{2}{*}{ EAST } & $-0.220^{* * *}$ & $-0.0501^{* * *}$ & $-0.273^{* * *}$ & $-0.208^{* * *}$ \\
\hline & $(0.0060)$ & $(0.0027)$ & $(0.0046)$ & $(0.0022)$ \\
\hline \multirow[t]{2}{*}{ CONST } & $-6.072^{* * *}$ & $-3.909^{* * *}$ & $-10.43^{* * *}$ & $-6.121^{* * *}$ \\
\hline & $(0.0288)$ & $(0.0154)$ & $(0.0219)$ & $(0.0130)$ \\
\hline \multirow[t]{2}{*}{$\ln \left(\sigma_{\alpha}^{2}\right)$} & $1.231^{* * *}$ & $-2.001^{* * *}$ & $1.063^{* * *}$ & $-1.522^{* * *}$ \\
\hline & $(0.0025)$ & $(0.0125)$ & $(0.0017)$ & $(0.0066)$ \\
\hline
\end{tabular}

Note: Standard errors in parentheses. ${ }^{*} \mathrm{p}<0.05,{ }^{* *} \mathrm{p}<0.01,{ }^{* * *} \mathrm{p}<0.001 . \mathrm{LF}_{\mathrm{t}-1}$ is the lagged labour force status. Initial LF is the labour force status from the first cycle. Models include year dummies and individual time averages of control variables. Age $=($ True Age -10$)$. 